\title{
Glycaemic control is associated with pre-eclampsia but not with pregnancy-induced hypertension in women with Type I diabetes mellitus
}

\author{
V.Hiilesmaa, L.Suhonen, K. Teramo \\ The Department of Obstetrics and Gynaecology, Helsinki University Central Hospital, Helsinki, Finland
}

\section{Abstract}

Aims/hypothesis. To investigate the association between glycaemic control and hypertensive pregnancy complications.

Methods. From 1988 to 1997, we followed up 683 consecutive non-selected pregnancies in women with Type I (insulin-dependent) diabetes mellitus. Glycaemic control was assessed by assay of $\mathrm{HbA}_{1 \mathrm{c}}$. Pre-eclampsia was defined as diastolic blood pressure of $90 \mathrm{mmHg}$ or more at the end of pregnancy after an increase of $15 \mathrm{mmHg}$ or more, combined with proteinuria of $0.3 \mathrm{~g}$ or more for $24 \mathrm{~h}$. Pregnancy-induced hypertension was defined similarly but without proteinuria. The same criteria were applied to a control group of 854 non-selected non-diabetic women.

Results. Pre-eclampsia developed in $12.8 \%$ of the women with diabetes (excluding those with nephropathy before pregnancy) and in $2.7 \%$ of the control women (odds ratio 5.2; $95 \%$ CI 3.3-8.4). In multiple logistic regression, glycaemic control, nulliparity, retinopathy and duration of diabetes emerged as statisti- cally significant independent predictors of pre-eclampsia. The adjusted odds ratios for pre-eclampsia were 1.6 (95\% CI 1.3-2.0) for each $1 \%$ increment in the $\mathrm{HbA}_{1 \mathrm{c}}$ value at 4-14 (median 7) weeks of gestation and $0.6(0.5-0.8)$ for each $1 \%$ decrement achieved during the first half of pregnancy. Changes in glycaemic control during the second half of pregnancy did not significantly alter the risk of pre-eclampsia. Unlike pre-eclampsia, the risk of pregnancy-induced hypertension was not associated with glycaemic control.

Conclusion/interpretation. In women with Type I diabetes, poor glycaemic control is associated with an increased risk of pre-eclampsia but not with a risk of pregnancy-induced hypertension. [Diabetologia (2000) 43: 1534-1539]

Keywords Adult, insulin-dependent diabetes mellitus, female, glycated hemoglobin A, hyperglycaemia, hypertension, pre-eclampsia, pregnancy, diabetes during pregnancy.
It has long been known that Type I (insulin-dependent) diabetes mellitus considerably increases the risk of pre-eclampsia and maternal and fetal co-morbidity [1-3]. The most important risk factor of pre-eclampsia in women with diabetes is nephropathy (White's class F) [1]. Even incipient nephropathy

Received: 23 June 2000 and in revised form: 9 August 2000

Corresponding author: V. Hiilesmaa, MD, PL 140, 00029 HYKS, Finland

Abbreviations: PIH, pregnancy-induced hypertension; OR, odds ratio. substantially increases the risk [4]. In addition, retinopathy and long duration of diabetes also increase the risk of pre-eclampsia [5-8].

Although an association between poor glycaemic control in early pregnancy and pre-eclampsia has been reported [4,7-11], it has not been observed by all [12]. It is not clear to what extent glycaemic control in early pregnancy might exert an effect on the occurrence of pre-eclampsia. Diabetic women with $\mathrm{HbA}_{1 \mathrm{c}}$ values greater than $8 \%$ could be at a greater risk of pre-eclampsia than those with values less than $8 \%$ [10]. It is not known whether the risk of pre-eclampsia in diabetic women with relatively good gly- 
caemic control differs from that in the general obstetric population. Furthermore, improvement of glucose control during pregnancy might reduce the risk of pre-eclampsia [9] but the magnitude of this reduction is not known. The results of previous studies have often been inconclusive due to small size, retrospective nature, lack of non-diabetic control subjects, or lack of multivariate analysis to control for confounding factors. Some of the studies are old and do not necessarily reflect the clinical setting of the last decade.

We carried out a 10-year population-based followup study of women with Type I diabetes to examine the effect of glucose control and several other factors on the occurrence of hypertensive-pregnancy complications.

\section{Subjects and methods}

Women with Type I diabetes. From 1988 to 1997, we followed up 683 pregnancies that lasted at least 20 weeks in 480 women diagnosed with Type I diabetes before pregnancy. As outpatients the women attended the Department of Obstetrics and Gynaecology, Helsinki University Central Hospital, at 2-6 week intervals and more frequently during the third trimester. This is the only centre responsible for the obstetric care of insulin-dependent women in the greater Helsinki area with a population of 1.5 million. The local ethics committee accepted the study protocol and subjects gave their informed consent.

Follow-up. The patients were advised to measure their blood glucose concentration at home five times a day, 2-3 days a week. Insulin was given using a long-acting preparation one to two times daily and a short-acting one at meals, mostly three to four times a day. An appointment with an ophthalmologist was arranged for the period of early pregnancy if the last evaluation of retinopathy had preceded the pregnancy by more than 6 months. Meticulous adherence to diet was promoted, and consultation with a dietitian arranged when needed.

Ultrasonography was carried out every $4-8$ weeks and monitoring by cardiotocography at each visit after 28 weeks and twice weekly after 34 weeks of gestation. The patients routinely underwent amniocentesis at 37 weeks (or earlier if needed) and delivery electively when the fetal lungs were mature. Caesarean delivery was preferred in patients of White's class $\mathrm{D}$ or higher and in others who developed additional risk factors such as fetal macrosomia or signs of fetal distress.

Control subjects. The control subjects comprised 854 non-selected pregnancies consecutively in 827 women residing in Kerava (a town in the middle of the hospital's catchment area) who participated in routine 18-week ultrasonography screening during 1993 and 1994. Women whose pregnancies ended before 20 weeks and those with gestational diabetes requiring insulin treatment, were excluded. The control subjects were seen by a doctor three to four times and by a midwife every 4 weeks until 28 weeks, every 2 weeks until 36 weeks and weekly thereafter.

Measurement of blood pressure and proteinuria. Blood pressure was measured after rest with the subject in a sitting or semi-recumbent position. The measurements were carried out as part of the routine clinical follow-up by midwives and nurses with long clinical experience.
Blood pressure during pregnancy was considered increased when the following two criteria were met at two measuring sessions of at least $24 \mathrm{~h}$ apart: First, diastolic pressure increased $15 \mathrm{mmHg}$ or more from the first measurement during pregnancy until the end of pregnancy, and second, the final level reached $90 \mathrm{mmHg}$ or more. Of the measurements, the second highest was used for analysis.

Urine was checked for protein by a dipstick method at each clinical visit. Results of " ++ " or repeated "+" were confirmed by quantitative analysis. A diagnosis of proteinuria was made if the amount of protein was $0.3 \mathrm{~g}$ or more $/ 24 \mathrm{~h}$.

Definitions of hypertensive pregnancy complications. Pre-eclampsia was defined as high blood pressure and proteinuria at the end of pregnancy, as described above. Pregnancy-induced hypertension (PIH) was defined as high blood pressure without proteinuria. These two conditions were thus mutually exclusive. A third category comprised subjects with neither of these conditions.

A different definition of pre-eclampsia and PIH had to be used for subjects with nephropathy before pregnancy (White's class F) who, by definition, already have constant proteinuria. They were considered to have pre-eclampsia or PIH if the above-mentioned blood pressure criteria alone were met.

Assessment of glycaemic control. Haemoglobin $\mathrm{A}_{1 \mathrm{c}}$ was assessed every 4 to 6 weeks by HPLC (Diamat, Bio-Rad Laboratories, Hercules, Calif., USA). The mean $\mathrm{HbA}_{1 \mathrm{c}}$ value as assessed by this method is $4.93 \%$ (SD 0.32) for healthy Finnish adults. Values of less than $5.6 \%$ ( $<$ mean +2 SD) were considered normal.

Three values of HbA were selected for this study: the first, the last and one during mid-pregnancy. Arithmetic differences between these three $\mathrm{HbA}_{1 \mathrm{c}}$ values were calculated for each patient and used as the criterion for changes of glycaemic control during pregnancy. The first $\mathrm{HbA}_{1 \mathrm{c}}$ assessment was carried out at a median of 7 weeks of gestation and in $93 \%$ by the end of the 14 th week. For the mid-pregnancy figure, the value obtained closest to 22 weeks was used (range 20-25 weeks). The last measurement during pregnancy occurred at a median of 2 weeks (range $0-4$ weeks) before delivery.

Statistical methods. Of 683 pregnancies in women with Type I diabetes and 854 control women, the power of this study to detect a doubling of the frequency of pre-eclampsia (6 vs $3 \%$ ) was $81 \%$ at a $p$-value of 0.05 . Categorial variables were tested by Fisher's exact probability test or the chi-squared test with the Armitage test for trends in proportions. Continuous variables were compared by using Student's $t$ test or the MannWhitney U test. Multiple logistic regression was used to assess the main effects of variables independently associated with the outcome. All tests were two-sided, and values of $p$ less than 0.05 were considered statistically significant. Arcus Quickstat Biomedical software (Longman Software Publishing, Cambridge, UK) and NCSS 2000 (NCSS Inc., Cary, N. C., USA) were used for the calculations.

\section{Results}

Baseline characteristics. Compared with the control women, the women with diabetes were nulliparous and had essential hypertension more often. No statistically significant differences were observed in the ages of mothers, numbers of smokers and social class defined by the womens' educational level (Table 1 ). 
Table 1. Characteristics of mothers with diabetes and control subjects

\begin{tabular}{|c|c|c|c|}
\hline & $\begin{array}{l}\text { Diabetes } \\
n=683\end{array}$ & $\begin{array}{l}\text { Control } \\
n=854\end{array}$ & $p$ \\
\hline \multicolumn{4}{|l|}{ General factors } \\
\hline Nulliparous & $335(49.1 \%)$ & $353(41.3 \%)$ & 0.003 \\
\hline Smoker & $95(13.9 \%)$ & $115(13.7 \%)$ & 0.9 \\
\hline Elementary school only & $46(9.4 \%)$ & $62(7.6 \%)$ & 0.2 \\
\hline Essential hypertension & $22(3.2 \%)$ & $10(1.2 \%)$ & 0.006 \\
\hline Pre-pregnancy nephropathy & $67(9.8 \%)$ & - & - \\
\hline Pre-pregnancy retinopathy & $237(34.7 \%)$ & - & - \\
\hline Pre-pregnancy insulin dose (IU, mean, SD) & $44 \pm 14.1$ & - & - \\
\hline Pre-pregnancy planning & $267(39 \%)$ & - & - \\
\hline
\end{tabular}

Means \pm SD.

Table 2. Characteristics of pregnancies

\begin{tabular}{lccc}
\hline & Diabetes & Control \\
$n=854$ & $p$ \\
& $n=683$ & $29.5 \pm 5.0$ & 0.3 \\
Maternal age at delivery (mean, SD) & $29.7 \pm 5.0$ & $21(2.5 \%)$ & 0.1 \\
$\quad<20$ years & $9(1.3 \%)$ & $19(2.2 \%)$ & 0.9 \\
$\quad \geq 40$ years & $16(2.3 \%)$ & $12(1.1 \%)$ & 0.1 \\
Twins & $17(2.5 \%)$ & $13.7 \pm 5.0$ & 0.1 \\
Weight gain (kg, mean, SD) & $13.4 \pm 5.2$ & $39.6 \pm 2.1$ & $<0.0001$ \\
Duration of gestation (weeks, mean, SD) & $36.7 \pm 2.3$ & $161(18.8 \%)$ & $<0.0001$ \\
Caesarean section rate & $524(76.7 \%)$ & &
\end{tabular}

Means \pm SD.

The women with diabetes had a significantly greater proportion of Caesarean sections and a shorter duration of gestation than the control subjects due to our practice of always doing elective Caesarean sections in White's class D and higher (Table 2).

Glycaemic control. In women with diabetes, glycaemic control improved significantly during the first half of pregnancy: the mean $\mathrm{HbA}_{1 \mathrm{c}}$ value dropped from $7.5 \%$ (SD 1.4 ) in early pregnancy to $6.4 \%$ (SD $1.0)$ in mid-pregnancy $(p<0.001)$. The mean $\mathrm{HbA}_{1 \mathrm{c}}$ value at the end of pregnancy was $6.7 \%$ (SD 1.1), which was significantly higher than at mid-pregnancy $(p<0.001)$.

Of the women with diabetes, 267 (39\% ) had counselling before pregnancy; their mean $\mathrm{HbA}_{1 \mathrm{c}}$ value up to 6 months before pregnancy was $7.5 \%$ (SD 1.3).

Risk factors of pre-eclampsia. Pre-eclampsia developed in $12.8 \%$ of the women with diabetes (excluding those with pre-pregnancy nephropathy) and in $2.7 \%$ of the control women (OR $5.2 ; 95 \%$ CI 3.3-8.4). A positive relation was observed between the $\mathrm{HbA}_{1 \mathrm{c}}$ value in early pregnancy with the occurrence of pre-eclampsia. Advanced White's class also showed an association with an increased risk of preeclampsia (Table 3).
We show the odds ratios for pre-eclampsia for the five variables that emerged as significant independent predictors in the logistic regression analysis done on the diabetic women (Table 4). Each $1 \%$ increment in the initial $\mathrm{HbA}_{1 \mathrm{c}}$ value (e.g. from 7.0 to $8.0 \%$ ) increased the risk of pre-eclampsia 1.6-fold. Improvement of glycaemic control reduced the risk 0.6 -fold for each $1 \%$ decrement of $\mathrm{HbA}_{1 \mathrm{c}}$ achieved until mid-pregnancy. The change of $\mathrm{HbA}_{1 \mathrm{c}}$ value from mid-pregnancy until the end of pregnancy did not significantly alter the risk of pre-eclampsia (OR $0.8 ; 95 \%$ CI $0.6-1.1$ for each $1 \%$ change).

The mothers' age, educational level, essential hypertension, twin pregnancy, BMI, pre-pregnancy insulin dose, insulin dose increment during pregnancy, smoking, or participation in pre-pregnancy planning did not show any pronounced association $(p>0.1)$ with pre-eclampsia.

Among the 267 diabetic women who had undergone pre-pregnancy planning, their pre-pregnancy $\mathrm{HbA}_{1 \mathrm{c}}$ value showed an association with the occurrence of pre-eclampsia in their subsequent pregnancy (OR 1.4, $95 \%$ CI 1.1-1.9 for each $1 \%$ increment).

Subgroup with a low risk of pre-eclampsia. Among the 683 women with Type I diabetes there were 138 $(20 \%)$ who were parous, had no nephropathy or ret- 
Table 3. Frequency of pre-eclampsia and PIH in subgroups of Type I diabetic women without pre-pregnancy nephropathy and in control subjects

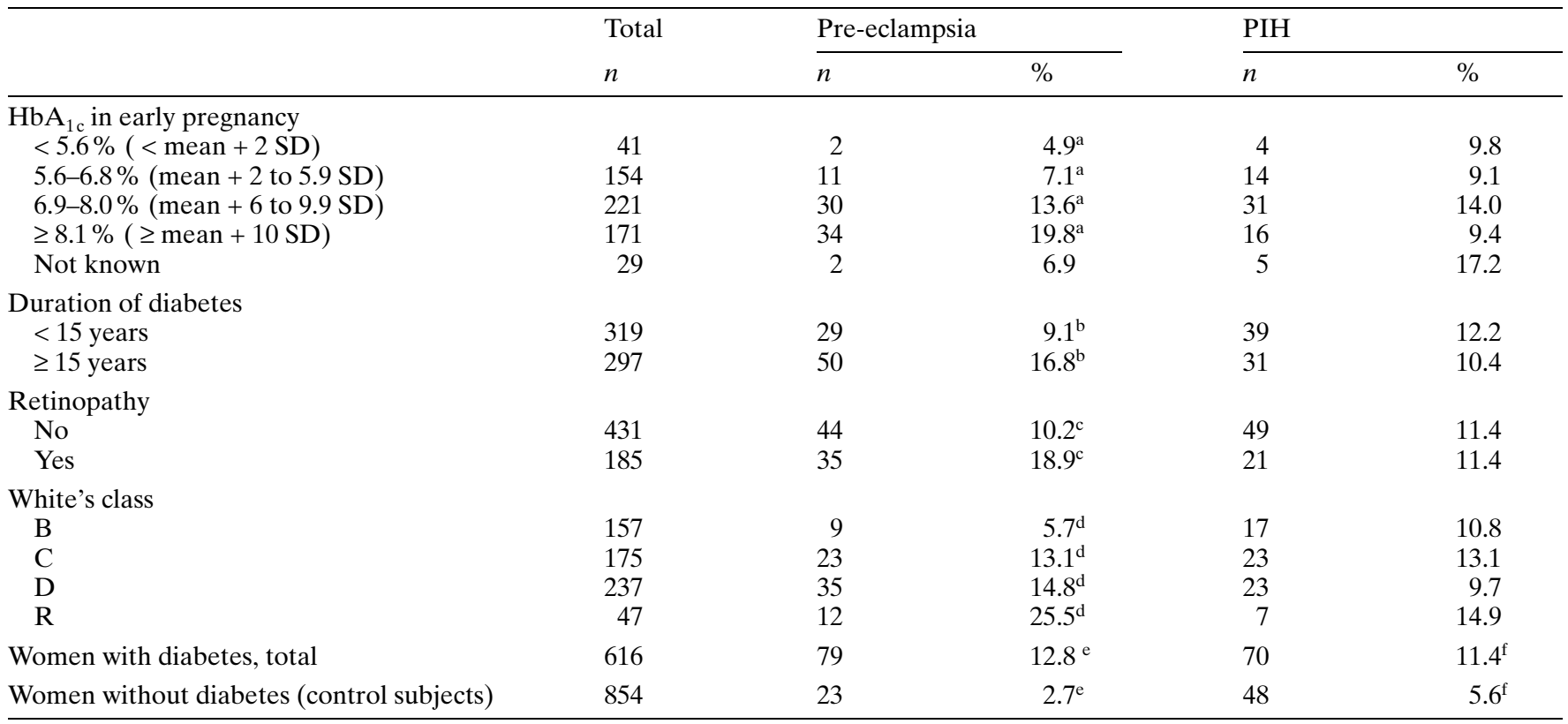

a,d $\chi^{2}$ test and Armitage test for trend: $p<0.0001 .{ }^{\mathrm{b}, \mathrm{c}} \chi^{2}$ test: $p=0.004$

e,f $\chi^{2}$ test: $p<0.0001$. Other differences were not statistically significant

Table 4. Factors associated with pre-eclampsia in 616 Type I diabetic women without pre-pregnancy nephropathy (White's classes $\mathrm{B}, \mathrm{C}, \mathrm{D}$ and $\mathrm{R}$ )

\begin{tabular}{|c|c|c|c|c|c|}
\hline & \multicolumn{2}{|c|}{ Unadjusted } & \multicolumn{3}{|c|}{ Adjusted } \\
\hline & OR & $95 \% \mathrm{CI}$ & OR & $95 \% \mathrm{CI}$ & $p$ \\
\hline Nulliparity & 2.9 & $1.9-4.5$ & 2.7 & $1.7-4.3$ & $<0.0001$ \\
\hline Duration of diabetes & $1.3^{\mathrm{a}}$ & $1.2-1.5$ & $1.2^{\mathrm{a}}$ & $1.0-1.5$ & 0.02 \\
\hline $\mathrm{HbA}_{1 \mathrm{c}}$ in early pregnancy & $1.3^{\mathrm{b}}$ & $1.1-1.5$ & $1.6^{\mathrm{b}}$ & $1.3-2.0$ & $<0.0001$ \\
\hline $\mathrm{HbA}_{1 \mathrm{c}}$ improvement until mid-pregnancy & $1.0^{\mathrm{c}}$ & $0.9-1.2$ & $0.6^{\mathrm{c}}$ & $0.5-0.8$ & $<0.0001$ \\
\hline
\end{tabular}

a increase of risk for each additional 5 years' duration

$\mathrm{b}$ increase of risk for each $1 \%$ increment of $\mathrm{HbA}_{1 \mathrm{c}}$

inopathy and had had diabetes for less than 15 years. Only four of them $(2.8 \%)$ developed pre-eclampsia, a rate similar to that of the control group $(2.7 \%)$.

Risk factors for PIH. Pregnancy-induced hypertension was observed in $11.4 \%$ of the women with diabetes (excluding those with pre-pregnancy nephropathy), compared with $5.6 \%$ of the control women (OR 2.2, 95\% CI 1.5-3.1). Unlike pre-eclampsia, no statistically significant association between high $\mathrm{HbA}_{1 \mathrm{c}}$ values and the occurrence of PIH was observed (Table 3 ). Neither was PIH associated with pre-pregnancy $\mathrm{HbA}_{1 \mathrm{c}}$ values, duration of diabetes, retinopathy or White's class. Only nulliparity showed a statistically significant association with PIH among women with diabetes (OR 1.8, $95 \%$ CI 1.1-3.0). Among the control subjects, nulliparity was also associated with PIH (OR 2.1, 95\% CI 1.1-3.7).
Patients with pre-pregnancy nephropathy (White's class $F$ ). Of the 67 patients with pre-pregnancy nephropathy, $38(57 \%)$ were considered as having pre-eclampsia or PIH on the basis of the blood pressure criteria.

Proteinuria without increased blood pressure. There were 53 women with diabetes $(7.8 \%)$ and 23 control subjects $(2.7 \%) \quad(p<0.001)$ who developed proteinuria by the end of pregnancy but did not meet our blood pressure criteria. Some of these patients, however, probably had "pre-eclampsia" with minimal or no increase in blood pressure. The remainder showed only pregnancy-induced proteinuria, which is known to occur occasionally in normal healthy subjects $[13,14]$. It was not possible to separate these two groups from one another due to the wellknown limitations in any definition of pre-eclampsia [15-18]. 


\section{Discussion}

Women with non-proteinuric Type I diabetes showed a five-fold risk of pre-eclampsia compared with the general obstetric cohort. This conforms with the results of previous studies in that there is a substantial increase of pre-eclampsia among women with Type I diabetes $[6,11]$. Our results also confirm that diabetic nephropathy before pregnancy considerably accentuates this risk [4]. Assessment of microalbuminuria (although not carried out in our study) might be a useful indicator of increased risk of pre-eclampsia before and during pregnancy [4].

The incidence of pre-eclampsia among women with diabetes has been reported to be 10 to $25 \%$ depending on material and definitions $[2,7,11,12]$ and is in accordance with our rate $(12.8 \%)$. Of the several possibilities to define high blood pressure, we chose to use diastolic pressure and took into account the increment from baseline and the final level during late pregnancy. Using the blood pressure level alone would have resulted in the inclusion of many women with chronic hypertension of $90 \mathrm{mmHg}$ or more with minimal or no increase during pregnancy [16]. On the other hand, an increase of $15 \mathrm{mmHg}$ alone in normotensive women has no effect on pregnancy outcome in most cases [19]. Because every definition of hypertension and pre-eclampsia is defective in some way $[17,18]$, compromises were also unavoidable in our study.

In addition to the overwhelming effects of nephropathy, the effects of nulliparity, retinopathy, duration of diabetes and glycaemic control emerged as statistically significant independent risk factors for pre-eclampsia. The mothers' age, educational level, essential hypertension and participation in pre-pregnancy planning did not show such an association.

In a recent Swedish report the mean $\mathrm{HbA}_{1 \mathrm{c}}$ value in early pregnancy was higher among those diabetic women who developed pre-eclampsia than in those who did not [11]. Another study conducted in the United States suggested an increased risk of pre-eclampsia associated with $\mathrm{HbA}_{1 \mathrm{c}}$ values higher than $8 \%[9,10]$. Our results support these findings, showing that the relation between the early-pregnancy $\mathrm{HbA}_{1 \mathrm{c}}$ value and the rate of pre-eclampsia is virtually linear. Each $1 \%$ increment from the initial $\mathrm{HbA}_{1 \mathrm{c}}$ value corresponded to a 1.6-fold increase in the risk of pre-eclampsia.

It has been suggested that reduction of a high $\mathrm{HbA}_{1 \mathrm{c}}$ value during pregnancy below a cut-off point of $8 \%$ reduces the risk of pre-eclampsia [9] but more detailed information on this relation is not available. Our results suggest that, after adjusting for the initial $\mathrm{HbA}_{1 \mathrm{c}}$ value and other statistically significant confounding factors, each $1 \%$ decrement in $\mathrm{HbA}_{1 \mathrm{c}}$ achieved by mid-pregnancy reduces the risk of preeclampsia by a factor of 0.6 . A change of $\mathrm{HbA}_{1 \mathrm{c}}$ value during the latter half of pregnancy did not statistically significantly influence the risk of pre-eclampsia.

Pre-pregnancy counselling of women with Type I diabetes is recommended for many reasons, of which the risk of fetal malformations due to hyperglycaemia is perhaps the most important. The association between high $\mathrm{HbA}_{1 \mathrm{c}}$ values and an increased risk of pre-eclampsia that we observed further stresses the need for appropriate counselling of young diabetic women before pregnancy.

Our results show the heterogeneity of women with Type I diabetes with regard to their risk of pre-eclampsia. For example, a parous woman without nephropathy or retinopathy, with diabetes for less than 15 years showed a risk of pre-eclampsia similar to that in women from the greater Helsinki area in general. This implies that obstetric follow-up of women with diabetes can be adjusted to each woman to a certain degree and not all of them need to be subjected to very intensive and expensive follow-up visits. There are many other factors, such as macrosomia [20] that must be taken into account when tailoring obstetric care for each of the mothers.

The risk of PIH among women with diabetes without nephropathy was twice that among control subjects. Unlike pre-eclampsia, the occurrence of PIH did not show an association with retinopathy or with the duration of diabetes. Neither was it associated with glycaemic control, which was also noted in the recent Swedish study [11]. This implies that pre-eclampsia and $\mathrm{PIH}$ in women with diabetes might be largely separate entities and the difference between these two disorders should probably be recognised in research as well as in clinical practice.

We conclude that poor glycaemic control in early pregnancy and failure to improve it during the first half of pregnancy are statistically significant risk factors for pre-eclampsia in women with Type I diabetes.

\section{References}

1. White P (1949) Pregnancy complicating diabetes. Am J Med 7: 609-616

2. Kyle GC (1963) Diabetes and pregnancy. Ann Intern Med 59 [Suppl 3]: 1-82

3. Pedersen J, Molsted-Pedersen L (1965) Prognosis of the outcome of pregnancies in diabetics: A new classification. Acta Endocrinol 50: 70-78

4. Combs CA, Rosenn B, Kitzmiller JL, Khoury JC, Wheeler BC, Miodovnik M (1993) Early-pregnancy proteinuria in diabetes related to preeclampsia. Obstet Gynecol 82: 802-807

5. Gabbe SG, Mestman JH, Freeman RK et al. (1977) Management and outcome of pregnancy and diabetes mellitus, classes B to R. Am J Obstet Gynecol 129: 723-732

6. Lufkin EG, Nelson RL, Hill LM, Melton LJ 3rd, O'Fallon WM, Evans AT 3rd (1984) An analysis of diabetic pregnancies at Mayo Clinic, 1950-79. Diabetes Care 7: $539-547$ 
7. Siddiqi T, Rosenn B, Mimouni F, Khoury J, Miodovnik M (1991) Hypertension during pregnancy in insulin-dependent diabetic women. Obstet Gynecol 77: 514-519

8. Rosenn B, Miodovnik M, Combs CA, Khoury J, Siddiqi TA (1993) Poor glycemic control and antepartum obstetric complications in women with insulin-dependent diabetes. Int J Gynaecol Obstet 43: 21-28

9. Hsu CD, Tan HY, Hong SF, Nickless NA, Copel JA (1996) Strategies for reducing the frequency of preeclampsia in pregnancies with insulin-dependent diabetes mellitus. Am J Perinatol 13: 265-268

10. Hsu CD, Hong SF, Nickless NA, Copel JA (1998) Glycosylated hemoglobin in insulin-dependent diabetes mellitus related to preeclampsia. Am J Perinatol 15: 199-202

11. Hanson U, Persson B (1998) Epidemiology of pregnancyinduced hypertension and preeclampsia in type 1 (insulindependent) diabetic pregnancies in Sweden. Acta Obstet Gynecol Scand 77: 620-624

12. Garner PR, D'Alton ME, Dudley DK, Huard P, Hardie M (1990) Preeclampsia in diabetic pregnancies. Am J Obstet Gynecol 163: 505-508
13. Bell SC, Halligan AW, Martin A et al. (1999) The role of observer error in antenatal dipstick proteinuria analysis. Br J Obstet Gynaecol 106: 1177-1180

14. Halligan AW, Bell SC, Taylor DJ (1999) Dipstick proteinuria: caveat emptor. $\mathrm{Br} \mathrm{J}$ Obstet Gynaecol 106: 1113-1115

15. Davey DA, MacGillivray I (1988) The classification and definition of the hypertensive disorders of pregnancy. Am J Obstet Gynecol 158: 892-898

16. Redman CWG, Jefferies M (1988) Revised definition of pre-eclampsia. Lancet i: 809-812

17. Brown MA, Buddle ML (1997) What's in a name? Problems with the classification of hypertension in pregnancy. J Hypertens 15: 1049-1054

18. Steer PJ (1999) The definition of pre-eclampsia. Br J Obstet Gynaecol 106: 753-755

19. North RA, Taylor RS, Schellenberg JC (1999) Evaluation of a definition of pre-eclampsia. Br J Obstet Gynaecol 106: $767-773$

20. Schwartz R, Teramo KA (1999) What is the significance of macrosomia? Diabetes Care 22: 1201-1205 